Southern Illinois University Carbondale

OpenSIUC

Publications

Department of Zoology

$4-2011$

\title{
Habitat Selection by Critically Endangered Florida Panthers across the Diel Period: Implications for Land Management and Conservation
}

Dave P. Onorato

Florida Fish and Wildlife Conservation Commission

Marc Criffield

Florida Fish and Wildlife Conservation Commission

Mark Lotz

Florida Fish and Wildlife Conservation Commission

Mark Cunningham

Florida Fish and Wildlife Conservation Commission

Roy McBride

See next page for additional authors

Follow this and additional works at: http://opensiuc.lib.siu.edu/zool_pubs

Published in Animal Conservation, Vol. 14, No. 2 (April 2011).

The definitive version is available at http://onlinelibrary.wiley.com/.

\section{Recommended Citation}

Onorato, Dave P., Criffield, Marc, Lotz, Mark, Cunningham, Mark, McBride, Roy, Leone, Erin H., Bass, Oron L. Jr. and Hellgren, Eric C. "Habitat Selection by Critically Endangered Florida Panthers across the Diel Period: Implications for Land Management and Conservation." (Apr 2011).

This Article is brought to you for free and open access by the Department of Zoology at OpenSIUC. It has been accepted for inclusion in Publications by an authorized administrator of OpenSIUC. For more information, please contact opensiuc@lib.siu.edu. 
Authors

Dave P. Onorato, Marc Criffield, Mark Lotz, Mark Cunningham, Roy McBride, Erin H. Leone, Oron L. Bass Jr., and Eric C. Hellgren 


\title{
$1 \quad$ Habitat selection by critically endangered Florida panthers
}

2 across the diel period: implications for land management and

3 conservation

4

5

6

Dave P. Onorato ${ }^{1 *}$, Marc Criffield ${ }^{1}$, Mark Lotz ${ }^{2}$, Mark Cunningham ${ }^{3}$, Roy McBride ${ }^{4}$, Erin H. Leone ${ }^{3}$, Oron L. Bass Jr. ${ }^{5}$, and Eric C. Hellgren ${ }^{6}$

${ }^{I}$ Fish and Wildlife Research Institute, Florida Fish and Wildlife Conservation Commission, Naples, FL, USA

${ }^{2}$ Division of Habitat and Species Conservation, Florida Fish and Wildlife Conservation Commission, Naples, FL, USA

${ }^{3}$ Fish and Wildlife Research Institute, Florida Fish and Wildlife Conservation Commission, Gainesville, FL, USA

${ }^{4}$ Rancher's Supply, Inc., Ochopee, FL, USA

${ }^{5}$ South Florida Natural Resource Center, Everglades National Park, Homestead, FL, USA

${ }^{6}$ Cooperative Wildlife Research Lab, Southern Illinois University-Carbondale, Carbondale, IL, USA

*Corresponding author. Email: dave.onorato@myfwc.com Phone: 239-417-6352 Fax: 239-417-6361

Short Title: Habitat selection by Florida panthers

\begin{abstract}
Decisions regarding landscape management, restoration, and land acquisition typically depend on land managers' interpretation of how wildlife selects habitat. Such assessments are particularly important for umbrella species like the endangered Florida panther (Puma concolor coryi), whose survival requires vast wildlands. Some interpretations of habitat selection by panthers have been criticized for using only morning locations in defining habitat use. We assessed habitat selection using a Euclidean distance analysis (EDA) and location data collected throughout the diel period from GPS collars deployed on 20 independent Florida panthers. We corroborated aspects of earlier analyses by demonstrating selection of forested habitats by panthers. We also confirmed selection of open habitats (i.e., marsh-shrub-swamps, prairie-grasslands), a novel result. Habitat selection did not vary by sex or season but varied by time of day. Panthers were located closer to wetland forests in the daytime and used prairie-
\end{abstract}


1 grasslands more at night. Our assessment of the effect of patch size on selection of forest

2 habitat revealed that panthers were not solely reliant on large patches (> $500 \mathrm{ha})$ but

3 utilized patches of all sizes ( $\leq 1 \mathrm{ha},>5-10 \mathrm{ha},>1000 \mathrm{ha}$, etc.). Our results emphasize the

4 importance of collecting panther location data throughout the diel period when assessing

5 habitat selection. Conservation strategies for panthers should consider a mosaic of

6 habitats, a methodology that will protect other sensitive flora and fauna in South Florida.

8 Key Words: conservation, endangered species, Euclidean distance analysis, Florida

9 panther, GPS collars, habitat selection, Puma concolor coryi

\section{Introduction}

12 Loss of habitat remains the greatest threat to many wildlife species, especially those that

13 are endangered and reliant upon large parcels of wildlands. Habitat loss results in

14 population declines, and smaller populations are less likely to persevere (Mills, 2007).

15 The fragmentation of wildlands that follows habitat loss can significantly affect species

16 that are wide ranging and exhibit low densities and low fecundity (e.g., large carnivores).

17 Therefore, the preservation of sufficient habitat to ensure the survival and promote the

18 recovery of endangered carnivores, such as the Florida panther (Puma concolor coryi),

19 requires that conservation planning be based on knowledge of habitat selection.

20 Furthermore, decisions related to panther habitat selection will affect many other species

21 across ecosystems, given the scale at which panthers range across the landscape.

22 Several studies have delineated habitat use by panthers (Belden et al., 1988;

23 Maehr \& Cox, 1995; Comiskey et al., 2002; Cox, Maehr \& Larkin, 2006; Kautz et al.,

24 2006; Land et al., 2008). Each of these studies highlighted the importance of forested 
1 habitats to panthers, but findings related to open habitats (e.g. marshes and prairies) could

2 be construed as inconclusive and unclear, probably an artifact of the data used in these

3 studies. All but Land et al. (2008) relied solely on VHF- telemetry data collected during

4 aerial surveys by the Florida Fish and Wildlife Conservation Commission (FWC) and the

5 National Park Service (NPS). These panther location data were typically collected during

6 the same hours of the morning (0700-1100 hrs) and on the same days of the week. Data

7 collected consistently during weekday mornings, although useful in answering some

8 ongoing research objectives (e.g., survival, fecundity, cause-specific mortality, morning

9 habitat use), cannot fully depict habitat selection across the diel period (Beier et al.,

10 2006). This limitation has been further substantiated in a habitat study of puma (P. c.) in

11 the western U.S. (Dickson, Jenness \& Beier, 2005). Using such data to decipher habitat

12 preferences of panthers has brought criticism and controversy (Gross, 2005; Beier et al., 13 2006).

14 Additional debate has stemmed from research that noted reliance of panthers on 15 only large patches (> 500 hectares) of forested habitat in South Florida (Maehr \& Cox,

16 1995; Maehr \& Deason, 2002) and their infrequent use of nonforested habitat $>90 \mathrm{~m}$

17 from forest patches (Maehr \& Cox, 1995). These analyses used the same VHF-telemetry

18 data collected only during morning hours, and therefore may be affected by biases

19 previously noted for panther habitat selection. Panther locations collected across the diel

20 period can provide a more complete depiction of how panthers use different forest patch

21 sizes, as well as nonforested habitat, perhaps clarifying some of the controversy

22 associated with previous analyses and permitting more appropriate habitat management

23 initiatives. 
Incorporating GPS into lightweight radiocollars has allowed evaluation of a range

2 of wildlife research issues, including habitat selection (Moe et al., 2007; Skarin et al.,

3 2008; Thurfjell et al., 2009), movement patterns (Bruggeman et al., 2007), road crossings

4 (Waller \& Servheen, 2005; Dodd et al., 2007), and predation rates (Knopff et al., 2009)

5 at a finer spatial resolution than possible with VHF telemetry. The FWC began deploying

6 GPS collars on panthers in 2002 and found no significant difference in habitat

7 preferences of panthers between morning data gathered by VHF and data gathered by

8 GPS (Land et al., 2008). To allay criticism regarding biases associated with data gathered

9 in the morning using VHF telemetry, Land et al. (2008) programmed GPS collars to

10 collect a majority of locations at night (1900-0700hrs). In the present study, to address

11 potential bias more thoroughly, we programmed GPS collars to collect data throughout

12 the diel period.

13 We used a Euclidean distance-based analysis (EDA; Conner, Smith \& Burger,

14 2003)to test hypotheses of habitat selection by Florida panthers. More specifically, we

15 predicted that panthers would use habitat within or closer to forested patches more during

16 the day than at night, given thermal cover afforded by forest for daytime rest sites (Kautz

17 et al., 2006). We also predicted that panthers would be found closer to or within open

18 habitats more frequently at night than during the day, given the ease of travel under cover

19 of darkness and the prey species often found in these habitat classes (Dickson et al.,

20 2005). Additionally, we expected that sex (Cox et al., 2006) and season (wet vs. dry)

21 would not affect habitat selection given the degree of overlap in panthers' home ranges

22 and the animals' generalist nature. Finally, we predicted that panther locations would be 
1 within a heterogeneous matrix of forest-patch sizes that affords improved habitat for prey

2 and hunting opportunities for predators (Kautz et al., 2006).

\section{Methods}

\section{Study Area}

5 South Florida has a subtropical climate, is topographically flat, and is characterized by

6 extensive permanent and ephemeral wetlands influenced by seasonal rains from May

7 through October (Duever et al., 1986). Wildland habitats include hardwood hammocks,

8 cypress forests, pine flatwoods, freshwater marshes, prairies, and grasslands (Davis,

9 1943); lands used by humans include citrus, croplands, pastureland, rock mining, and

10 areas of low- and high-density residential development. Our study area encompassed a

11 large portion of the range of the breeding population of panthers in South Florida. This

12 population exists within wildlands bordered by the urban areas of Miami-Fort

13 Lauderdale to the east, Fort Myers-Naples to the west, the Caloosahatchee River to the

14 north, and Florida Bay to the south (Fig. 1). One male panther (FP130) that had

15 previously dispersed north of the Caloosahatchee River and established a definitive home

16 range was fitted with a GPS collar for this study and monitored outside the breeding

17 range until his collar failed.

18 Our capture efforts focused not only on the core population (panthers inhabiting

19 large parcels of protected public lands important to the demographic stability of the

20 population) in southwestern Florida (comprising portions of Big Cypress National

21 Preserve north of I-75, Florida Panther National Wildlife Refuge, and Fakahatchee Strand

22 Preserve State Park), but also on panthers residing in Everglades National Park and on

23 public and private lands bordering the edges of the Florida panther primary zone (South 
1 Florida lands essential to survival and long-term viability of Florida panthers; Kautz et

2 al., 2006) in the northern and western extent of its range (Fig. 1). These areas are vital to

3 panther conservation for several reasons. First, panthers in Everglades National Park are

4 somewhat isolated from the core population in southwestern Florida due to the

5 semipermeable barrier posed by the Shark River Slough (Fig. 1). Second, habitat use in

6 Everglades National Park is concentrated in upland areas, adjacent to the urban fringe of

7 south Miami and Homestead. Third, habitat along the northern and western edges of the

8 primary zone is being encroached upon by urban development. Finally, habitat in

9 Okaloacoochee Slough State Forest (OK Slough SF; Fig. 1) is adjacent to the dispersal

10 zone (lands that should be protected from development for a dispersal corridor; Kautz et

11 al., 2006), and monitoring patterns of habitat selection there may help in assessing

12 whether south-central Florida north of the Caloosahatchee River could be naturally

13 recolonized. Data from protected lands in Big Cypress National Preserve south of I-75

14 were not available (Fig. 1). Thus, we focused on the use of habitat by panthers in areas

15 affected by habitat loss rather than unaffected areas.

\section{Capture, GPS collaring, data compilation, and estimation of home range}

17 We used trained hounds and houndsmen supplied by Livestock Protection Company

18 (Alpine, Texas) to capture independent-age Florida panthers. We deployed five models of

19 GPS collars produced by four manufacturers (Table 1), including Advanced Telemetry

20 Systems G2110 (Isanti, Minnesota, USA), Lotek GPS3300s (New Market, Ontario,

21 Canada), Followit Tellus and Tellus-GSM (Lindesberg, Sweden), and Telonics TGW-

223401 (Mesa, Arizona, USA). Fix schedules programmed into collars varied (Table 1) but

23 all were programmed to attempt fixes throughout the diel period via either a frequent or 
1 staggered fix schedule (see supplementary materials). A preliminary field trial for

2 assessing location error associated with the GPS collar models used in this study revealed

3 a mean error of $33.9 \mathrm{~m}(\mathrm{SE}=8.1, n=3210$ fixes; J. Benson and D. Onorato, FWC,

4 unpublished report).

$5 \quad$ Data from all GPS collars were compiled and visually displayed in ArcGIS 9.3

6 (ESRI, Redlands, CA, USA).We qualified each fix as occurring during day (0700-1859

7 hrs) or night (1900-0659 hrs), and during the dry (15 October-14 May) or wet (15 May-

814 October) season. We used GPS locations to estimate each panther's home range with

$9100 \%$ minimum convex polygons (MCP, see supplementary materials Fig. S1) in ArcGIS

109.3 using Hawth's Tools (Beyer, 2004).

\section{Habitat analyses}

12 We combined 43 land-cover classes categorized by the FWC (Kautz, Stys \&

13 Kawula, 2007) into six broader classes (see supplementary materials Table S1) after Land

14 et al. (2008): upland forest, wetland forest, dry prairie-grassland, marsh-shrub-swamp,

15 agriculture, and "other" (comprising all remaining types, including open water, mangrove

16 swamp, exotic plants, and urban). Land-cover data were in raster format and correlated

17 with ground conditions present in 2003 at a 30-m resolution, the most current and

18 comprehensive available for our study area.

19 We chose the EDA of Conner et al. (2003) to assess third-order habitat selection

20 (habitat selection within the home range; Johnson, 1980), because it uses individual

21 panthers, not GPS locations, as the sampling unit and because of its use in recent studies

22 (Cox et al., 2006; Kautz et al., 2006; Land et al., 2008). The EDA compares the distance

23 between animal locations and the nearest pixel of each land-cover class (i.e., habitat use) 
1 to the distance between random points plotted within the $100 \% \mathrm{MCP}$ home range and the

2 nearest pixel of each land-cover class (i.e., habitat availability). We generated 20,000

3 random points in a uniform distribution within each home range after testing a range of

4 points (1000 to 30,000) to assess when the variance of the mean distance in each land-

5 cover class began to stabilize (Moyer, McCown \& Oli, 2008). Distances between points

6 and land-cover classes were determined using the Euclidean distance tool in the Spatial

7 Analyst extension in ArcGIS 9.3 and via the intersect points option in Hawth's Tools

8 (Beyer, 2004).

9 A vector of six distance ratios was created for each panther by dividing the mean

10 distance of its locations from each land-cover class by the mean distance of random

11 points to each land-cover class (i.e., one distance ratio per land-cover class). A distance

12 ratio $>1$ indicates avoidance (i.e., the mean distance from a panther's location to a land-

13 cover class is greater than the mean distance from random points within the home range

14 to the same land-cover class), whereas a distance ratio $<1$ indicates selection. The

15 expected value for these ratios under the null hypothesis of no selection is 1 , and we used

16 MANOVA (PROC GLM) to test whether panthers were exhibiting habitat selection. A

17 significant MANOVA test result indicates nonrandom use of land-cover classes as the

18 mean distance vector differs from 1 . We subsequently tested for selection or avoidance of

19 individual habitats using univariate $t$-tests; paired $t$-tests were used to rank habitats by

20 preference. We also tested the fixed effects of sex, season, and time of day. For seasonal

21 and time-of-day analyses, the individual animal ID was included in the model as a

22 random effect to account for data collected at both levels (wet or dry season; day or

23 night) for each animal. A significant MANOVA test result for each fixed effect indicates 
1 a difference in land-cover use between the categories (female or male; wet or dry season;

2 day or night). In the event of a significant fixed effect, we reviewed the GLM results to

3 assess differences in selection between levels of fixed effects (e.g., night vs. day) within

4 each land-cover class.

$5 \quad$ We assessed whether panthers were located closer to or farther from forest

6 patches of different sizes using an EDA. We used ArcGIS 9.3 to create a forest-patch

7 layer that combined upland and wetland forest layers with three additional land-cover

8 classes (melaleuca [Melaleuca quinquenervia] and Australian pine [Casuarina sp.],

9 invasive exotic trees established in South Florida; mangrove swamps, which are typically

10 inundated) included in the "other" habitat category (see supplementary materials Table

11 S1). Panthers have been documented within those habitats via field sign and VHF

12 telemetry data, although they used them infrequently. To encompass a range of sizes, we

13 qualified seven patch-size classes (0.1-1 ha, 1.1-5 ha, 5.1-10 ha, 10.1-100 ha, 100.1-

14500 ha, 500.1-1000 ha, and > 1000 ha). Statistical analyses were as described for the

15 habitat analysis. We also determined the distance of panther locations in unforested

16 habitat from the nearest forest patch to descriptively quantify the prevalence of those

17 data. Finally, we used a Kolmogorov-Smirnov two-sample distribution test (PROC

18 NPAR1WAY) to test whether the frequency distribution of locations within 11 distance-

19 from-forest groups differed between daytime and night. All statistical tests were

20 completed in SAS 9.1 (SAS Institute, Cary, NC, USA) and the EDA used code adapted

21 from Conner and Plowman (2001).

22 Results 
1 We collared 20 independent-aged (i.e., $\geq 1.5$ years old) panthers ( 10 females, 10 males)

2 between February 2005 and February 2009 (Table 1). Age at capture ranged from 1.5 to

313.3 years, and mean time collared was 306 days (range $=113-610$ days). We collected

458,212 locations over 79,147 attempts (74\% fix success rate). Successful fixes included a

5 nearly even ratio of night:day fixes (53\%:47\%). The ratio of wet:dry season fixes was

6 uneven (37\%:63\%) because all panthers were initially collared during the dry season

7 when field conditions were favorable for capture. This uneven ratio may have affected

8 our assessment of the impact of season on habitat selection.

9 Panthers exhibited habitat selection at the third-order level $\left(F_{6,13}=25.31, P<\right.$

10 0.001). Panthers selected upland forest, wetland forest, marsh-shrub-swamp, and prairie-

11 grassland habitats (Table 2). Agricultural and the "other" land-cover classes were used in

12 proportion to their availability; no class was avoided. Habitat selection did not vary by

13 main effects of $\operatorname{sex}\left(F_{6,13}=2.30, P=0.099\right)$ or season $\left(F_{6,12}=2.46, P=0.087\right)$, but it did

14 vary by time of day $\left(F_{6,14}=15.27, P<0.001\right)$. Panthers used wetland forests more during

15 the day than night, but they used prairie grasslands more at night (Fig. 2). Use of the

16 remaining selected land-cover classes (upland forests and marsh-shrub-swamp) did not

17 differ significantly between night and day (Fig. 2). Even though the "other" land-cover

18 class was used in proportion to its availability, panthers used areas near or in the "other"

19 class significantly more at night than during the day (Fig. 2).

20 Panthers exhibited selection of the smallest (0.1-1.0 ha), intermediate (5.1-10.0

21 ha), and largest ( $>1000$ ha) classes of forest-patch size $\left(F_{7,12}=8.49, P<0.001\right)$ within

22 home ranges (Table 3). All other patch sizes were used in proportion to availability.

23 Pairwise comparisons to rank forest-patch size revealed no significant differences, 
1 probably because all forest-to-patch-size ratios were $<1$, demonstrating that panthers

2 tend to be closer to forest patches than farther from them (ratio > 1). Nevertheless, $41.0 \%$

$3(23,850)$ of locations were outside of forest patches and $28.2 \%$ of those were $>90 \mathrm{~m}$ from

4 a forest patch. The frequency of locations within 11 distance-from-forest categories was

5 distributed differently between night and day (KSa $=4.30, P<0.0001$; Fig. 3). Overall,

$624.6 \%$ and $30.8 \%$ of fixes $>90 \mathrm{~m}$ from forests were made during the day and night,

7 respectively.

\section{Discussion}

9 Findings related to habitat selection by Florida panthers have consistently caused

10 controversy that has affected conservation and recovery of this endangered species (Beier

11 et al., 2006). Our results represent a rigorous assessment of panther habitat selection for

12 several reasons. Our total sample of collared individuals comprised $17 \%$ of the recent

13 (2007) minimum population count (McBride et al. 2008). Panthers that we collared used

14 a large portion of the current breeding range in South Florida (see supplementary

15 materials Fig. S1). By collecting panther location data across the diel period, we

16 alleviated biases associated with studies relying on data collected from VHF-collared

17 panthers in mornings (0700-1100hrs) only, which underestimated the use of more open

18 habitats. A study using data collected solely at night would have similar biases (i.e.,

19 underestimation of the use of forested habitats).

20 Our results concur in some respects with analyses using VHF data collected in the

21 morning (Belden et al., 1988; Maehr \& Cox, 1995; Cox et al., 2006; Kautz et al., 2006;

22 Land et al., 2008). Panthers have repeatedly been shown to select forested habitat either

23 within their home range (third-order selection; Belden et al., 1988; Cox et al., 2006; Land 
1 et al., 2008) or within a study area (second-order selection; Kautz et al., 2006). In our

2 study, panther locations were significantly closer than expected to upland and wetland

3 forest classes, and these ranked highest in pairwise comparisons with other land-cover

4 classes. Given consistent results from several studies using data collected in the morning

5 or across the diel period and using different analytical methodologies (i.e., compositional

6 analysis, [Aebischer, Robertson \& Kenward, 1993]; EDA), we conclude that forested

7 land-cover classes are of vital importance to Florida panthers in South Florida.

8 Forested habitats provide a variety of attributes critical to panther demography

9 and conservation. Females choose den sites in forested habitats (Benson, Lotz \& Jansen,

10 2008), especially woodlands with dense patches of saw palmetto (Serenoa repens).

11 Forested habitats also provide rest sites, particularly important during South Florida's

12 hot, humid summers. Research in western North America has noted that pumas must be

13 able to approach prey to a certain minimal distance to improve their stalking success

14 (Hornocker, 1970; Logan \& Irwin, 1985; Beier, Choate \& Barrett, 1995). Forests and the

15 associated edge with adjacent open habitats may improve hunting success in pumas

16 (Laundré \& Loxterman, 2007). We often encountered panther kills in forests adjacent to

17 more open habitats. Data collected from a GPS-GSM-collared male panther permitted us

18 to locate six kill sites within a 20-day period in June 2008 (M. Criffield, FWC, unpubl.

19 data). Three of these kill sites were on the edge between forested and open habitats; all

20 were $<33 \mathrm{~m}$ from an edge (mean $=13.7 \mathrm{~m}, \mathrm{SE}=4.8 \mathrm{~m}$ ). Although this sample size is

21 small, the data highlight the importance of forested and open landscapes to panthers.

22 Panthers may use the edge of forested habitat as stalking cover to ambush white-tailed

23 deer (Odocoileus virginianus) or feral hogs (Sus scrofa) feeding in open areas, and then 
1 drag their kill into forested areas to feed. Feral hogs are habitat generalists, using a mix of

2 open- and closed-canopy habitats (Ilse \& Hellgren, 1995; Gabor, Hellgren \& Silvy,

3 2001), for foraging and shade, respectively. Our findings thus emphasize not only the

4 importance of forest to panther conservation, but also the benefits of heterogeneous

5 habitat matrices and their higher proportion of edge.

6 Defining the use of forested habitats as a source of cover for panthers warrants

7 additional discussion. If we define cover as "any physical or biological feature or

8 arrangement of features that provides shelter from weather or concealment from or for

9 predators" (Bolen \& Robinson, 1999), then we note that panthers rely on more than just

10 forested habitat for cover. Nonforest but densely vegetated habitats also provide

11 sufficient cover. They could include thick patches of tall sawgrass (McBride, 2001) to

12 expanses of mature saw palmetto adjacent to pine or oak forests. The use of varied

13 habitats as cover by panthers is not unexpected given the persistence of other puma

14 populations in deserts (Davis \& Schmidly, 1994; Logan \& Sweanor, 2001) characterized

15 by minimal forest cover.

16 The most novel result of our study was the documentation of selection of prairie-

17 grassland and marsh-shrub-swamp patches. Previous studies that assessed habitat

18 selection using the EDA at the third-order level with VHF data (Cox et al., 2006; Land et

19 al., 2008) did not show that panthers selected these open habitats. Cox et al. (2006)

20 reported that panthers avoided open wetlands (which included freshwater, sawgrass, and

21 cattail marshes and wet prairies), a category synonymous with our marsh-shrub-swamp

22 (which included cover types compiled by Cox et al. [2006] as well as shrub swamps).

23 Studies assessing habitat selection by pumas in western North America have 
1 demonstrated avoidance of open habitats such as grasslands (Logan \& Irwin, 1985;

2 Dickson \& Beier, 2002). Both studies collected data with VHF collars and primarily

3 during the day, constraints the researchers acknowledged may have biased their findings

4 on a species known to be active during crepuscular periods. In fact, in a follow-up study

5 by Dickson et al. (2005) that included nocturnal data, avoidance of grasslands was not

6 apparent. This result substantiates the need to collect habitat-selection data during the

7 daytime and at night to comprehensively delineate habitat requirements.

8 White-tailed deer and feral hogs would be expected to use open habitats such as

9 grasslands because of the plentiful food sources there (Gabor et al., 2001). Feral hogs in

10 southern latitudes are typically nocturnal and forage primarily on grasses and

11 underground plant parts (Ilse \& Hellgren, 1995; Taylor \& Hellgren, 1997). In addition,

12 plants in marsh-shrub-swamps compose a major portion of deer diets (Labisky et al.,

13 2003). Open areas also permit prey to be more vigilant regarding predators.

14 The only other published study that has used GPS to assess panther habitat

15 selection (Land et al., 2008) did not reveal selection for open land-cover classes, although

16 it did observe an increase in the percentage of panther locations in prairie-grasslands at

17 night. We believe our results were different from those of Land et al. (2008) because 1)

18 their sample size was smaller (12 vs. 20 independent panthers); 2) their study area was

19 smaller; and 3) 82.6\% of their GPS fixes were collected from 1900 to $0700 \mathrm{hrs}$. We

20 collected a nearly even percentage of daytime vs. nighttime fixes. Although panthers are

21 said to rest during much of the diurnal period, we documented movements throughout the

22 diel period with sightings, motion-activated cameras, and via GPS data collected using

23 frequent acquisition rates (e.g., hourly or every 15 minutes). Collecting data from 
1 individual panthers across the diel period provides the most complete characterization of

2 habitat use by panthers and forgoes the need to qualify conclusions related to VHF data

3 collected at morning locations or to model nighttime habitat selection based on daytime

4 locations (Comiskey et al., 2002).

5 As expected, panthers were located closer to forested habitats during the day than

6 at night, although night and daytime use was significantly different only in wetland

7 forests (Fig. 2). Forested habitats are likely to provide panthers with respite from the

8 tropical South Florida climate, which can be extreme ( $>35^{\circ} \mathrm{C}, 95 \%$ humidity) at some

9 times of day. We predicted that panthers would use open habitats more frequently during

10 the nocturnal period as opposed to during the day. Indeed, selection for prairie-grasslands

11 was significantly greater during the nocturnal period than during the diurnal period.

12 Marsh-shrub-swamps were not selected differently during the two time-of-day classes.

13 We attribute the increased use of prairie-grasslands by panthers at night to optimization

14 of predation opportunities and facilitation of movements across the landscape, activities

15 that predators may carry out more covertly during darkness than in light. Dickson et al.

16 (2005) allude to this idea in their findings on pumas in California, suggesting that open

17 areas such as grasslands are used by pumas to traverse areas or to stalk and pursue prey.

18 Previous studies using VHF data in assessing the relationship of forest-patch size

19 and distance from forest with the likelihood that an area supported panthers have been

20 contentious (Maehr \& Cox, 1995; Maehr \& Deason, 2002) because of their potential

21 impacts on panther recovery. These studies indicated that panther occupancy of forest

22 patches declined significantly in patches of $<500$ ha, and the resulting Panther Habitat

23 Evaluation Model used this criterion when assessing the impact on panthers of 
1 development in available habitat (Maehr \& Deason, 2002). In contrast, our findings

2 indicate, as did those of Kautz et al. (2006), that panthers use a variety of forest-patch

3 sizes, often within a matrix of open habitats. Our results have shown that panthers use

4 habitat outside of forest patches (i.e., open land-cover classes) more frequently (in $41.0 \%$

5 of locations) than previously reported (Maehr \& Cox, 1995). Maehr \& Cox (1995), using

6 VHF data collected during the morning hours, concluded that $96 \%$ of panther locations

7 were located either in preferred land-cover classes or within $90 \mathrm{~m}$ of them. These classes

8 included hardwood hammocks, hardwood swamps, and cypress swamps (synonymous

9 with land-cover classes that comprised our forest-patch landscape class). In our study,

$1028.2 \%$ of panther locations were $>90 \mathrm{~m}$ from our forest patch land-cover class. The most

11 likely explanations for the difference in the results between these studies are that (1) we

12 collected data throughout the diel period and (2) distances measured relative to forest

13 patches were more accurate than distances estimated by an observer in an aircraft making

14 rapid spatial judgments from visual and auditory cues. Use by panthers of a

15 heterogeneous matrix of forest-patch sizes, as well as open areas, is consistent with the

16 adaptable nature of Puma concolor across its range (Logan \& Sweanor, 2001). The

17 historic distribution of puma from northwestern Canada through Patagonia in South

18 America (Young \& Goldman, 1946) attests to this. Franklin et al. (1999) descriptively

19 noted the use by Patagonian pumas of forests and grasslands, depending on time of day.

20 The other large felid in the western hemisphere, the jaguar (Panthera onca), is also wide-

21 ranging and has adapted to a variety of landscapes, from evergreen woodlands to

22 semidesert grasslands (Hatten, Averill-Murray \& van Pelt, 2005). The Florida panther has

23 adapted to a variety of ecosystems, as illustrated by its presence in 1) vast areas 
1 dominated by sawgrass (Everglades National Park); 2) cypress-dominated landscapes in

2 portions of Big Cypress National Preserve; and 3) the more northern extents of its range,

3 associated with forested uplands and prairie-grasslands. In summary, it appears that a

4 mélange of small, medium, and large forest patches dispersed among open areas may

5 increase the probability that panthers will occupy land-cover in South Florida. Such

6 diverse landscapes may provide suitable prey (white-tailed deer and feral hogs) while

7 providing more edge and therefore more opportunities to hunt successfully.

\section{Conclusions}

9 The selection by panthers of open habitats that include marsh-shrub-swamps and

10 prairie-grasslands was a novel finding that may have ramifications on how resource-

11 management agencies attempt to preserve, rehabilitate, and purchase habitat for panthers.

12 For example, the U.S. Fish and Wildlife Service (USFWS) uses a compensation tool that

13 generates the number of panther habitat units used to define impacts of development on

14 panther habitat and subsequently recommend appropriate mitigation. The USFWS uses

15 this tool in formulating biologically defensible opinions relating to federal actions that

16 have an adverse impact on the Florida panther. The tool's current incarnation specifies

17 that habitats selected by panthers should be ranked with higher scores than those used

18 according to availability or that are avoided. Our findings, supported by data collected

19 across the diel period, may merit review by the USFWS with regard to scores assigned to

20 habitat containing marsh-shrub-swamps and prairie-grasslands, especially when

21 interspersed with forested habitats.

22 Reclassifying panthers and delisting involves establishing three viable populations

23 of 240 panthers (subadults and adults) for at least 12 years (USFWS, 2008). Pumas rely 
1 on extensive, interconnected landscapes even to maintain minimal populations (Logan \&

2 Sweanor, 2001). For the Florida panther, whose habitat is much more fragmented than

3 that of western pumas, the area of a male's home range is still $435-650 \mathrm{~km}^{2}$ (Onorato et

$4 a l ., 2010)$. This scale underscores the challenges faced by researchers and managers in

5 Florida, who need to pursue coordinated objectives with regional governments and

6 private entities to propagate expansion of the population from the confines of South

7 Florida. Although suitable relocation sites have been identified in other southeastern

8 states (Thatcher, Van Manen \& Clark, 2006) and in central Florida (Thatcher, van Manen

9 \& Clark, 2009), sociopolitical challenges must be overcome for a release program to be

10 successful.

\section{Acknowledgments}

12 We thank the citizens of Florida who continue to support research and management on

13 the Florida panther by the FWC via the purchase of Florida Panther license plates,

14 revenues from which funded this study in its entirety via the Florida Panther Research

15 and Management Trust Fund. We thank the following individuals for their assistance and

16 cooperation on different facets of panther research related to this study: C. McBride, A.

17 Smith, L. Oberhoffer, M. Alvarado, and D. Shindle. R. Kawula, J. Benson, and K.

18 Hussey provided GIS assistance. C. Belden, J. Colvocoresses, B. Crowder, J. Gore, D.

19 Land, and T. O'Meara provided editorial comments on drafts of this manuscript. In

20 addition, we thank the staffs at the Big Cypress National Preserve, Big Cypress Seminole

21 Indian Reservation, Collier-Seminole State Park, Corkscrew Regional Ecosystem

22 Watershed, Corkscrew Swamp Sanctuary, Florida Panther National Wildlife Refuge,

23 Fakahatchee Strand Preserve State Park, Picayune Strand State Forest, Okaloacoochee 
1 Slough State Forest, and South Florida Water Management District for their continued

2 support of our research and management efforts.

\section{References}

4 Aebischer, N. J., Robertson, P. A. \& Kenward, R. E. (1993). Compositional analysis of 5 habitat use from animal radio-tracking data. Ecology. 74, 1313-1325.

6 Beier, P., Choate, D. \& Barrett, R. H. (1995). Movement patterns of mountain lions

7 during different behaviors. J. Mammal. 76, 1056-1070.

8 Beier, P., Vaughan, M. R., Conroy, M. J. \& Quigley, H. (2006). Evaluating scientific

9 inferences about the Florida panther. J. Wildl. Manag. 70, 236-245.

10 Belden, R. C., Frankenberger, W. B., Mcbride, R. T. \& Schwikert, S. T. (1988). Panther

11 habitat use in Southern Florida. J. Wildl. Manag. 52, 660-663.

12 Benson, J. F., Lotz, M. A. \& Jansen, D. (2008). Natal den selection by Florida panthers.

13 J. Wildl. Manag. 72, 405-410.

14 Beyer, H. L. (2004). Hawth's analysis tools for ArcGIS. Available at $15 \quad$ www.spatialecology.com.

16 Bolen, E. G. \& Robinson, W. L. (1999). Wildlife ecology and management. 4th edn.

17 Upper Saddle River, NJ: Prentice Hall.

18 Bruggeman, J. E., Garrott, R. A., White, P. J., Watson, F. G. R. \& Wallen, R. (2007).

19 Covariates affecting spatial variability in bison travel behavior in Yellowstone

$20 \quad$ National Park. Ecol. Appl. 17, 1411-1423.

21 Comiskey, E. J., Bass, O. L., Jr., Gross, L. J., Mcbride, R. T. \& Salinas, R. (2002).

22 Panthers and forests in South Florida: an ecological perspective. Conserv. Ecol. 6,

$23 \quad 18$.


1 Conner, L. M. \& Plowman, B. W. (2001). Using Euclidean distances to assess nonrandom habitat use. In: Radio tracking and animal populations: 275-290. Millspaugh, J. J. , Marzluff, J. M. (Eds.). San Diego, CA: Academic Press.

4 Conner, L. M., Smith, M. D. \& Burger, L. W. (2003). A comparison of distance-based and classification-based analyses of habitat use. Ecology. 84, 526-531.

6 Cox, J. J., Maehr, D. S. \& Larkin, J. L. (2006). Florida panther habitat use: new approach to an old problem. J. Wildl. Manag. 70, 1778-1785.

8 Davis, J. H. J. (1943). The natural features of southern Florida. Florida Geological 9 Survey. Tallahassee, FL.

10 Davis, W. B. \& Schmidly, D. J. (1994). The mammals of Texas. Austin, TX: Texas Parks $11 \quad$ and Wildlife Press.

12 Dickson, B. G. \& Beier, P. (2002). Home-range and habitat selection by adult cougars in southern California. J. Wildl. Manag. 66, 1235-1245.

14 Dickson, B. G., Jenness, J. S. \& Beier, P. (2005). Influence of vegetation, topography, and roads on cougar movement in southern California. J. Wildl. Manag. 69, 264-

17 Dodd, N. L., Gagnon, J. W., Boe, S. \& Schweinsburg, R. E. (2007). Assessment of elk highway permeability by using Global Positioning System telemetry. J. Wildl. Manag. 71, 1107-1117.

20 Duever, M. J., Carlson, J. E., Meeder, J. F., Duever, L. C., Gunderson, L. H., Riopelle, L. 21 A., Alexander, T. R., Myers, R. L. \& Spangler, D. P. (1986). The Big Cypress 22 National Preserve. National Audubon Society. New York, NY. 
1 Franklin, W. L., Johnson, W. E., Sarno, R. J. \& Iriarte, J. A. (1999). Ecology of the Patagonia puma Felis concolor patagonica in southern Chile. Biol. Conserv. 90, $33-40$.

4 Gabor, T. M., Hellgren, E. C. \& Silvy, N. J. (2001). Multi-scale habitat partitioning in sympatric suiforms. J. Wildl. Manag. 65, 99-110.

6 Gross, L. (2005). Why not the best? how science failed the Florida panther. PLoS Biol. 3, e333.

Hatten, J. R., Averill-Murray, A. \& Van Pelt, W. E. (2005). A spatial model of potential jaguar habitat in Arizona. J. Wildl. Manag. 69, 1024-1033.

Hemson, G., Johnson, P., South, A., Kenward, R., Ripley, R. \& Macdonald, D. (2005). Are kernels the mustard? Data from global positioning system (GPS) collars suggests problems for kernel home-range analyses with least-squares crossvalidation. J. Anim. Ecol. 74, 455-463.

Hornocker, M. G. (1970). An analysis of mountain lion predation upon mule deer and elk in the Idaho Primitive Area. Wildl. Monogr., 39pp.

Ilse, L. M. \& Hellgren, E. C. (1995). Resource partitioning in sympatric populations of collared peccaries and feral hogs in Southern Texas. J. Mammal. 76, 784-799.

Johnson, D. H. (1980). The comparison of usage and availability measurements for evaluating resource preference. Ecology. 61, 65-71.

Kautz, R., Kawula, R., Hoctor, T., Comiskey, J., Jansen, D., Jennings, D., Kasbohm, J., Mazzotti, F., Mcbride, R., Richardson, L. \& Root, K. (2006). How much is enough? Landscape-scale conservation for the Florida panther. Biol. Conserv. 130, 118-133. 
1 Kautz, R., Stys, B. \& Kawula, R. (2007). Florida vegetation 2003 and land use change between 1985-89 and 2003. Fla. Sci. 70, 12-23.

3 Knopff, K. H., Knopff, A. A., Warren, M. B. \& Boyce, M. S. (2009). Evaluating global

4 positioning system telemetry techniques for estimating cougar predation

5 parameters. J. Wildl. Manag. 73, 586-597.

6 Labisky, R. F., Hurd, C. C., Oli, M. K. \& Barwick, R. (2003). Foods of white-tailed deer

7 in the Florida Everglades: The significance of Crinum. Southeast. Nat. 2, 261-

8270.

9 Land, E. D., Shindle, D. B., Kawula, R. J., Benson, J. F., Lotz, M. A. \& Onorato, D. P. 10 (2008). Florida panther habitat selection analysis of concurrent GPS and VHF 11 telemetry data. J. Wildl. Manag. 72, 633-639.

12 Laundré, J. W. \& Loxterman, J. (2007). Impact of edge habitat on summer home range 13 size in female pumas. Am. Midl. Nat. 157, 221-229.

14 Logan, K. A. \& Irwin, L. L. (1985). Mountain lion habitats in the Big Horn Mountains, 15 Wyoming. Wildl. Soc. Bull. 13, 257-262.

16 Logan, K. A. \& Sweanor, L. L. (2001). Desert puma: evolutionary ecology and 17 conservation of an enduring carnivore. Washington, D.C: Island Press.

18 Maehr, D. S. \& Cox, J. A. (1995). Landscape features and panthers in Florida. Conserv. Biol. 9, 1008-1019.

20 Maehr, D. S. \& Deason, J. P. (2002). Wide-ranging carnivores and development permits:

21 constructing a multi-scale model to evaluate impacts on the Florida panther.

22 Clean Technologies and Environmental Policy. 3, 398-406. 
1 Mcbride, R. (2001). Current panther distribution, population trends, and habitat use:

4 Mills, L. S. (2007). Conservation of wildlife populations: demography, genetics and report of field work, fall 2000-winter 2001. United States Fish and Wildlife Service, South Florida Ecosystem Office. Vero Beach, FL. management. Malden, MA: Blackwell Publishing.

Moe, T. F., Kindberg, J., Jansson, I. \& Swenson, J. E. (2007). Importance of diel behaviour when studying habitat selection: examples from female Scandinavian brown bears (Ursus arctos). Can. J. Zool. 85, 518-525.

Moyer, M. A., Mccown, J. W. \& Oli, M. K. (2008). Scale-dependent habitat selection by female Florida black bears in Ocala National Forest, Florida. Southeast. Nat. 7, $111-124$.

Onorato, D., Belden, C., Cunningham, M., Land, D., Mcbride, R. \& Roelke, M. (2010). Long-term research on the Florida panther (Puma concolor coryi): historical findings and future obstacles to population persistence. In: Biology and conservation of wild felids: pp. 453-469. Macdonald, D. , Loveridge, A. (Eds.). Oxford, UK: Oxford University Press.

Skarin, A., Danell, O., Bergstrom, R. \& Moen, J. (2008). Summer habitat preferences of GPS-collared reindeer Rangifer tarandus tarandus. Wildl. Biol. 14, 1-15.

Taylor, R. B. \& Hellgren, E. C. (1997). Diet of feral hogs in the western South Texas Plains. Southwest. Nat. 42, 33-39.

Thatcher, C. A., Van Manen, F. T. \& Clark, J. D. (2006). Identifying suitable sites for Florida panther reintroduction. J. Wildl. Manag. 70, 752-763. 
1 Thatcher, C. A., Van Manen, F. T. \& Clark, J. D. (2009). A Habitat Assessment for

2 Florida Panther Population Expansion into Central Florida. J. Mammal. 90, 918925.

4 Thurfjell, H., Ball, J., Åhlén, P.-A., Kornacher, P., Dettki, H. \& Sjöberg, K. (2009).

$5 \quad$ Habitat use and spatial patterns of wild boar Sus scrofa (L.): agricultural fields

$6 \quad$ and edges. Eur. J. Wildl. Res. 55, 517-523.

7 USFWS (2008). Florida panther recovery plan (Puma concolor coryi), third revision.

$8 \quad$ United States Fish and Wildlife Service. Atlanta, GA.

9 Waller, J. S. \& Servheen, C. (2005). Effects of transportation infrastructure on grizzly

10 bears in northwestern Montana. J. Wildl. Manag. 69, 985-1000.

11 Young, S. P. \& Goldman, E. A. (1946). The puma, mysterious American cat. Part I.

12 History, life habits, economic status, and control. Washington, D.C.: The

13 American Wildlife Institute.

14 
1 Figure 1. Map depicting the breeding range of the Florida panther (lightly shaded green;

2 Kautz et al. 2006) and major public land holdings (darker shading) in South Florida,

3 USA. Key to abbreviations: BCNP, Big Cypress National Preserve; CREW, Corkscrew

4 Regional Ecosystem Watershed; EVER, Everglades National Park; FSPSP, Fakahatchee

5 Strand Preserve State Park; FPNWR, Florida Panther National Wildlife Refuge; OK

6 Slough SF, Okaloacoochee Slough State Forest; PSSF, Picayune Strand State Forest. The

7 Caloosahatchee River is the northern border of the present breeding range of the Florida

8 panther. Panthers in Everglades National Park are partially isolated from the core

9 population in Southwest Florida by the semi-permeable barrier of the Shark River

10 Slough.

11 Figure 2. Comparison of habitat selection within land-cover classes during different

12 times of day by Florida panthers, fitted with GPS collars, in South Florida. Land-cover

13 classes selected for by panthers (ratios $<1, P<0.05$ ) included upland forests, wetland

14 forests, prairie-grasslands and marsh-shrub-swamps. Dashed line represents the border

15 between distance ratios that were $<$ or $>1$. Landcover classes used differently $(P<0.05)$

16 between night and day are denoted with *.

17 Figure 3. Distribution of the distances (m) of GPS locations of Florida panthers from

18 forest patches in South Florida. A total of 23,850 of 58,212 locations were in nonforested

19 patches. A total of 13,811 and 10,039 locations were in nonforested patches during the

20 night and day, respectively. 
1 Table 1. Data describing locations collected from Florida panthers fitted with GPS

2 collars by the Florida Fish and Wildlife Conservation Commission, February 2005-

3 February 2009 in South Florida, USA. The GPS collar models are described in the text;

4 GPS days include the total number of days of GPS data collection. Daytime fixes were

5 collected from 0700 hours to 1859 hours.

\begin{tabular}{|c|c|c|c|c|c|c|c|c|}
\hline ID & Sex & Age & $\begin{array}{r}\text { GPS } \\
\text { Model }\end{array}$ & $\begin{array}{l}\text { GPS } \\
\text { Days }\end{array}$ & $\begin{array}{r}\text { Fix } \\
\text { Schedule }\end{array}$ & $\begin{array}{r}\text { Fixes } \\
\text { Acquired }\end{array}$ & $\begin{array}{r}\text { Percent Fix } \\
\text { Success }\end{array}$ & $\begin{array}{r}\text { Percent Fix } \\
\text { Night:Day }\end{array}$ \\
\hline FP48 & F & 13.3 & Tellus & 610 & hourly & 10732 & 74.4 & $51: 49$ \\
\hline FP94 & F & 6.5 & Tellus & 427 & hourly & 8286 & 80.9 & $51: 49$ \\
\hline FP110 & $\mathrm{F}$ & 5.5 & Lotek & 504 & 7 hours & 1156 & 66.6 & $51: 49$ \\
\hline FP113 & F & 4.5 & Lotek & 310 & 7 hours & 743 & 69.7 & $53: 47$ \\
\hline FP121 & $\mathrm{F}$ & 4.5 & $\mathrm{ATS}^{\mathrm{a}}$ & 174 & 7 hours & 366 & 58.7 & $55: 45$ \\
\hline FP128 & $\mathrm{F}$ & 6.5 & ATS & 230 & 7 hours & 438 & 55.4 & $55: 45$ \\
\hline FP130 & M & 2 & Tellus & 429 & hourly & 8253 & 81.0 & $54: 46$ \\
\hline FP131 & M & 6.5 & Tellus & 394 & hourly & 7358 & 77.8 & $51: 49$ \\
\hline FP135 & M & 2.75 & Telonics & 253 & 7 hours & 529 & 60.9 & 59:41 \\
\hline FP137 & M & 3.5 & Tellus-GSM & 236 & 2 hours & 2038 & 72.1 & $52: 48$ \\
\hline FP142 & $\mathrm{F}$ & 2.5 & Lotek & 273 & 3 hours & 1530 & 69.9 & $54: 46$ \\
\hline FP143 & M & 1.5 & Lotek & 341 & 7 hours & 690 & 58.9 & $56: 44$ \\
\hline FP146 ${ }^{\mathrm{b}}$ & M & 3 & Telonics & 835 & 7 hours & 1919 & 67.0 & $56: 44$ \\
\hline FP148 & $\mathrm{F}$ & 2.5 & ATS & 311 & 7 hours & 583 & 54.6 & $58: 42$ \\
\hline FP149 & $\mathrm{F}$ & 2 & ATS & 114 & 7 hours & 283 & 72.2 & $57: 43$ \\
\hline FP155 & M & 2.5 & Tellus-GSM & 285 & $15 \mathrm{~min} /$ hourly $^{\mathrm{c}}$ & 5689 & 73.5 & $54: 46$ \\
\hline FP156 & M & 2.5 & Tellus-GSM & 203 & hourly/4 hours ${ }^{\mathrm{c}}$ & 469 & 29.4 & $54: 46$ \\
\hline FP157 & M & 3 & Tellus-GSM & 113 & $30 \mathrm{~min} /$ hourly $^{\mathrm{c}}$ & 1966 & 67.4 & $51: 49$ \\
\hline FP160 & $\mathrm{F}$ & 5 & Tellus-GSM & 118 & hourly/4 hours ${ }^{c}$ & 481 & 43.7 & $56: 44$ \\
\hline FP167 & M & 2.5 & Tellus-GSM & 261 & hourly/4hours ${ }^{\mathrm{c}}$ & 4705 & 5872 & $54: 46$ \\
\hline
\end{tabular}


$1 \quad{ }^{b}$ FP146 was initially collared on 27 February 2006 with a Telonics GPS collar and recollared on 29 January 2007 with 2 another Telonics GPS collar allowing for a continuous data set of 835 days.

$3{ }^{c}$ These Tellus-GSM collars collected data across a range of fix schedules ( $\mathrm{min} / \mathrm{max}$ ) for a concurrent project. A

4 majority of the locations for these collars were collected using the longer fix attempt interval. 
5 Table 2. Third-order habitat selection determined via Euclidean distance analysis using

6 GPS location data from 20 independent Florida panthers monitored in South Florida.

7 Ratios $<1.0$ indicate habitat preference, whereas ratios $>1.0$ indicate avoidance $(P<$

8 0.05). Habitats sharing any common letter rank were similarly preferred or avoided $(P>$

90.05 , Bonferroni adjustment) or used in proportion to their availability.

10

\begin{tabular}{lrrr}
\hline Habitat & Ratio & $P$-value & Ranks \\
\hline Upland forest & 0.532 & $<0.001$ & $\mathrm{~A}$ \\
Wetland forest & 0.620 & $<0.001$ & $\mathrm{AB}$ \\
Prairie-grassland & 0.785 & 0.001 & $\mathrm{~B}$ \\
Marsh-shrub-swamp & 0.799 & 0.004 & $\mathrm{BC}$ \\
Agricultural & 1.039 & 0.618 & $\mathrm{C}$ \\
Other & 1.047 & 0.555 & $\mathrm{C}$ \\
\hline
\end{tabular}

11

12

13 
1 Table 3. Forest patch size selection determined via Euclidean distance analysis using

2 GPS location data from 20 independent Florida panthers monitored in South Florida.

3 Ratios $<1.0$ indicate habitat preference and ratios $>1.0$ indicate avoidance $(P<0.05)$.

4

\begin{tabular}{lrrrrr}
\hline $\begin{array}{l}\text { Forest patch } \\
\text { size (ha) }\end{array}$ & $\begin{array}{r}\text { Number of } \\
\text { patches }\end{array}$ & $\begin{array}{r}\text { Mean patch } \\
\text { size (ha) }\end{array}$ & Sum (ha) & Ratio & $P$-value \\
\hline$\leq 1.0$ & 646353 & 0.2 & 119639 & 0.893 & 0.025 \\
$>1-5$ & 42937 & 2.2 & 92623 & 0.920 & 0.142 \\
$>5-10$ & 7774 & 7.0 & 54286 & 0.906 & 0.023 \\
$>10-100$ & 8187 & 27.1 & 221989 & 0.891 & 0.100 \\
$>100-500$ & 838 & 200.3 & 167838 & 0.947 & 0.309 \\
$>500-1000$ & 88 & 707.5 & 62259 & 0.979 & 0.586 \\
$>1000$ & 94 & 6431.0 & 604509 & 0.710 & 0.010 \\
\hline
\end{tabular}

5 


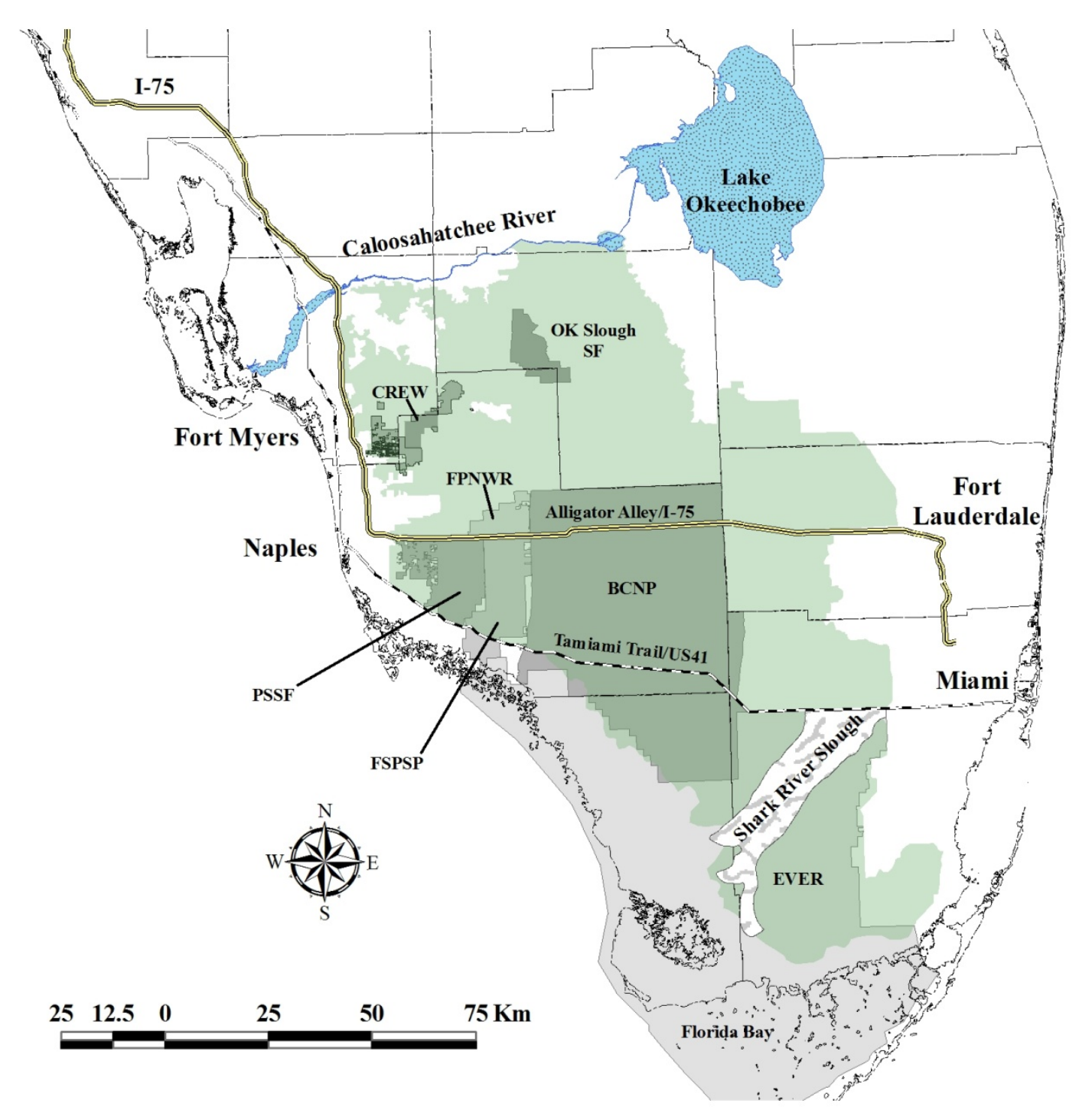




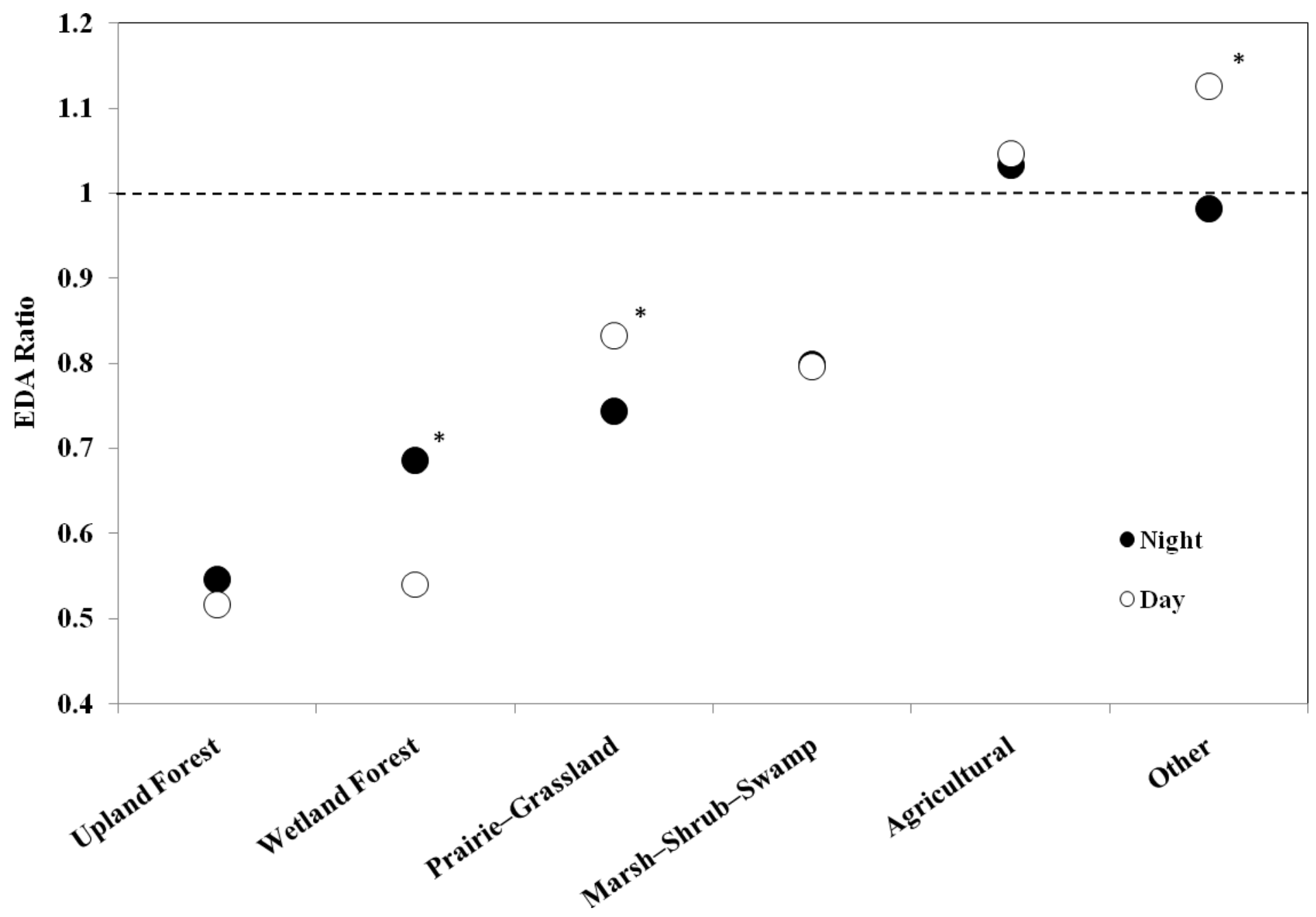




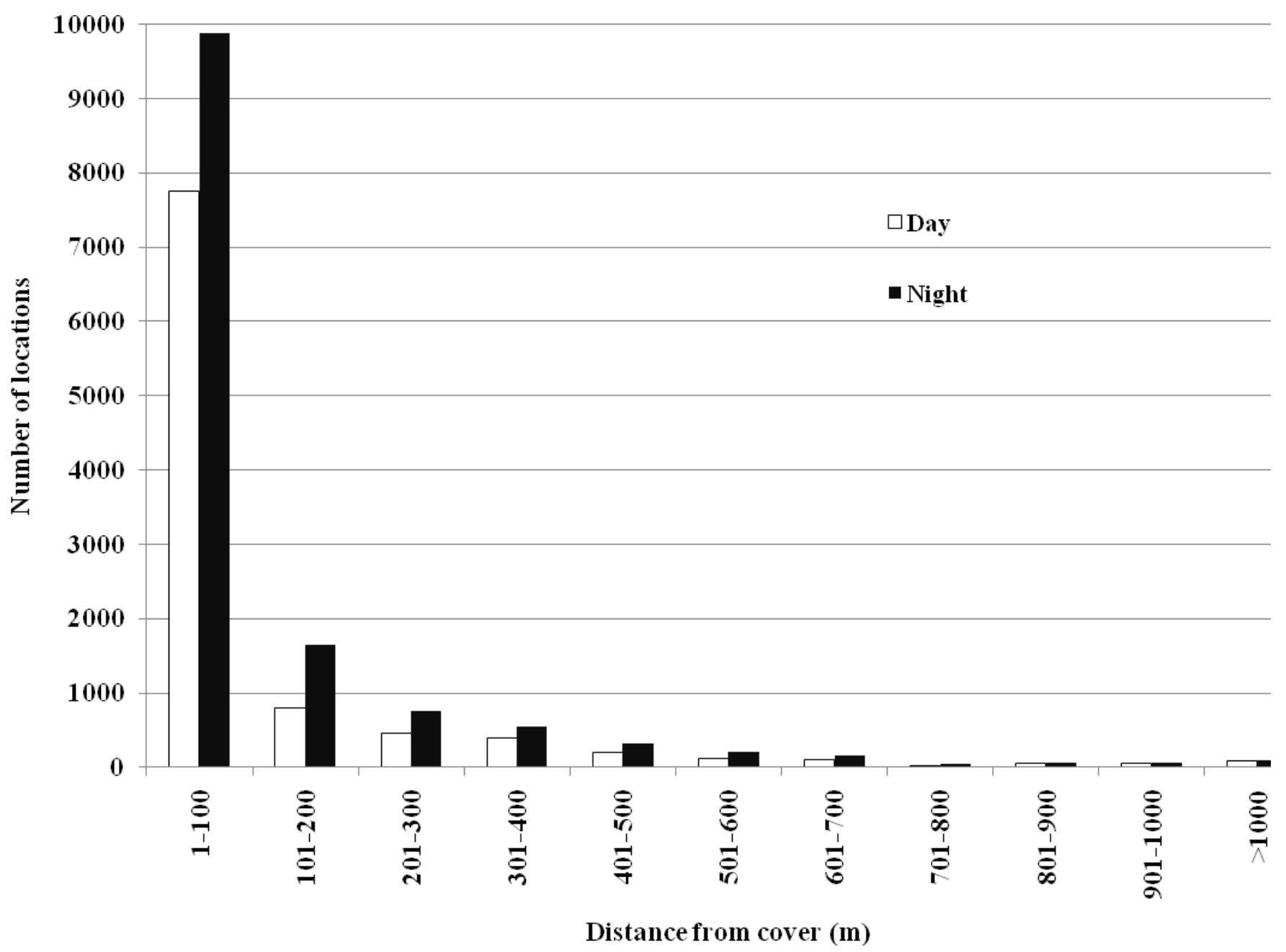




\section{Onorato et al. Supplementary Material}

2

3 Methods

4

11 attempt in every hour of a 24-hr diel period. Followit Tellus-GSM collars sent locations

12 via e-mail when panthers were within range of a GSM (Global System for Mobile

13 Communications) mobile telephone tower. Most data obtained with these GSM collars

14 were collected either every two hours or hourly.

\section{Habitat analyses}

23 including areas not used by panthers. Also, for the African lion (Panthera leo), Hemson

24 et al. (2005) noted that estimates of home ranges using kernel-density estimators with

25 least-squares cross validation could be unreliable when applied to large GPS data sets.

26 We believe our GPS data for the Florida panther would have been similarly affected by

27 these issues if we had implemented a fixed-kernel technique. Additionally, we used MCP 
1 home ranges because we wanted our analysis to be comparable to that of Land et al.

2 (2008), the only other published study of habitat selection in panthers that used GPS data.

\section{References}

4 Beyer, H. L. (2004). Hawth's analysis tool for ArcGIS. Available at

$5 \quad \underline{w w w . s p a t i a l e c o l o g y . c o m}$

6 Hemson, G., Johnson, P., South, A., Kenward, R., Ripley, R. \& Macdonald, D. (2005).

7 Are kernels the mustard? Data from global positioning system (GPS) collars

8 suggests problems for kernel home-range analyses with least-squares cross-

$9 \quad$ validation. J. Anim. Ecol. 74, 455-463.

10 Land, E. D., Shindle, D. B., Kawula, R. J., Benson, J. F., Lotz, M. A. \& Onorato, D. P. 11 (2008). Florida panther habitat selection analysis of concurrent GPS and VHF

12 telemetry data. J. Wildl. Manag. 72, 633-639.

13

14

15 
1 Figure S1. Map depicting the $100 \%$ minimum convex polygon (MCP) home ranges for

220 independent Florida panthers fitted with GPS collars in South Florida, February 2005-

3 February 2009. These ranges were used to determine habitat available to panthers, which

4 was then used in assessments of habitat selection by Euclidean distance analysis. 
1 Table S1. Land cover classes from Kautz et al. (2007), reclassified for the analysis of

2 habitat selection by Florida panthers. The forest patch category was used to define

3 patches of habitat inclusive of forests $(0=$ nonforested; $1=$ forested $)$. Forest land cover

4 classes not found within the study area (e.g., bottomland hardwood forest) were not

5 included.

\begin{tabular}{|c|c|c|}
\hline Original Land cover Class & Forest Patch Land cover Class & Reclassified Land cover Class \\
\hline Coastal strand & 0 & Other \\
\hline Sand/beach & 0 & Other \\
\hline Xeric oak scrub & 0 & Other \\
\hline Sand pine scrub & 0 & Other \\
\hline Sandhill & 0 & Other \\
\hline Dry prairie & 0 & Prairie-grassland \\
\hline Mixed pine-hardwood forest & 1 & Upland forest \\
\hline Hardwood hammocks and forest & 1 & Upland forest \\
\hline Pinelands & 1 & Upland forest \\
\hline Cabbage palm-live oak hammock & 1 & Upland forest \\
\hline Tropical hardwood hammock & 1 & Upland forest \\
\hline Freshwater marsh and wet prairie & 0 & Marsh-shrub-swamp \\
\hline Sawgrass marsh & 0 & Marsh-shrub-swamp \\
\hline Cattail marsh & 0 & Marsh-shrub-swamp \\
\hline Shrub swamp & 0 & Marsh-shrub-swamp \\
\hline Bay swamp & 0 & Other \\
\hline Cypress swamp & 1 & Wetland forest \\
\hline Cypress/pine/cabbage palm & 1 & Wetland forest \\
\hline Mixed wetland forest & 1 & Wetland forest \\
\hline Hardwood swamp & 1 & Wetland forest \\
\hline Hydric hammock & 0 & Other \\
\hline Bottomland hardwood forest & 0 & Other \\
\hline Salt marsh & 0 & Other \\
\hline Mangrove swamp & 1 & Other \\
\hline Scrub mangrove & 0 & Other \\
\hline Tidal flat & 0 & Other \\
\hline Open water & 0 & Other \\
\hline Shrub and brushland & 0 & Other \\
\hline Grassland & 0 & Prairie-grassland \\
\hline Bare soil/clearcut & 0 & Other \\
\hline Improved pasture & 0 & Prairie-grassland \\
\hline Unimproved/woodland pasture & 0 & Prairie-grassland \\
\hline Sugar cane & 0 & Agriculture \\
\hline Citrus & 0 & Agriculture \\
\hline Row/field crops & 0 & Agriculture \\
\hline Other agriculture & 0 & Agriculture \\
\hline Exotic plants & 0 & Other \\
\hline Australian pine & 1 & Other \\
\hline Melaleuca & 1 & Other \\
\hline Brazilian pepper & 0 & Other \\
\hline High-impact urban & 0 & Other \\
\hline Low-impact urban & 0 & Other \\
\hline Extractive & 0 & Other \\
\hline
\end{tabular}




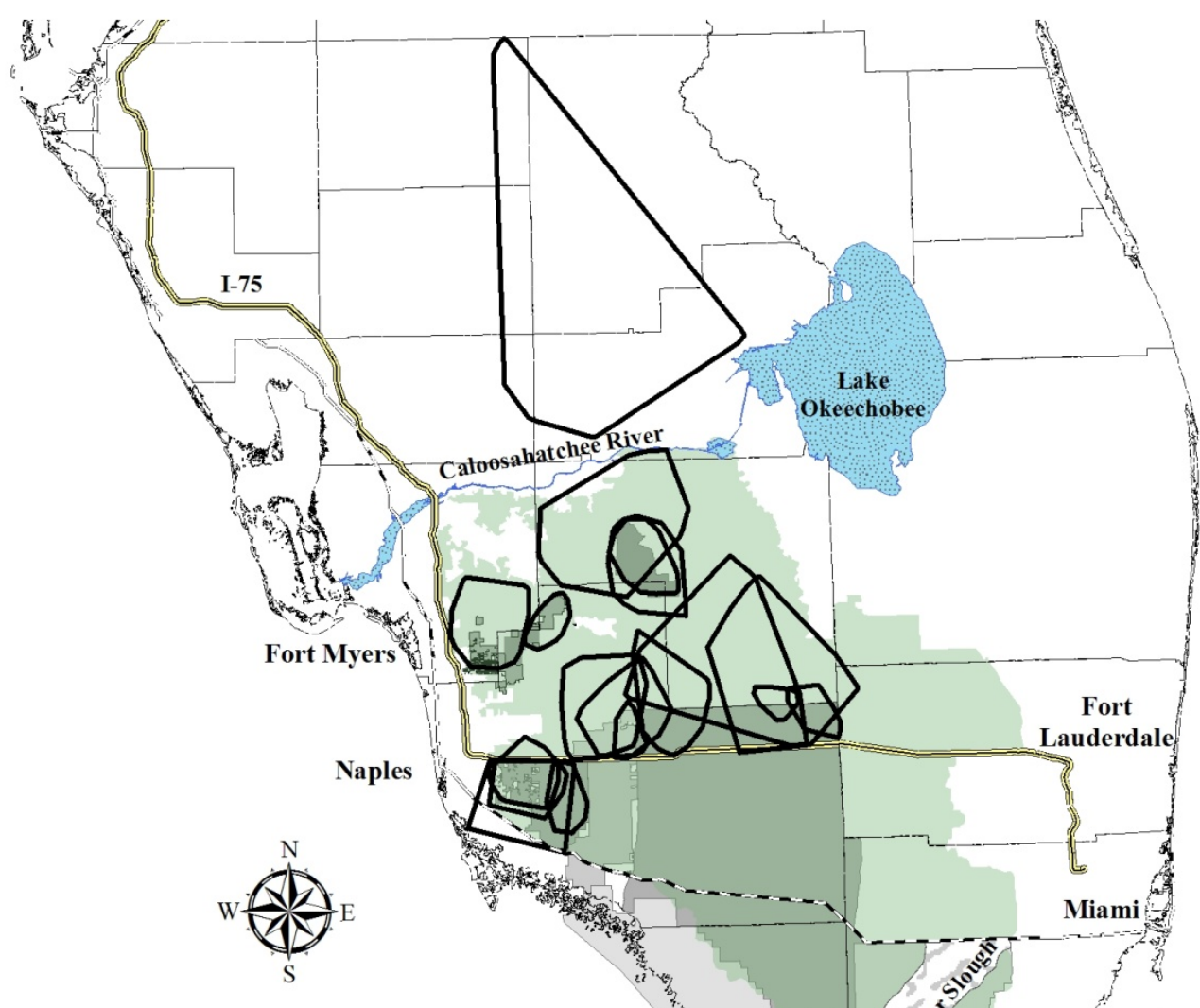

$\begin{array}{llllll}25 & 12.5 & 0 & 25 & 50 & 75\end{array}$ 